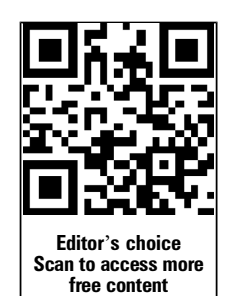

free content

\title{
A double-blind, randomised, placebo-controlled trial of oral midazolam plus oral ketamine for sedation of children during laceration repair
}

\author{
Shiri Barkan, ${ }^{1}$ Rachelle Breitbart, ${ }^{1,2}$ Galit Brenner-Zada, ${ }^{1}$ Michal Feldon, ${ }^{1}$ Amit Assa, ${ }^{1}$ \\ Michal Toledano, ${ }^{3}$ Sofia Berkovitch, ${ }^{3}$ Itai Shavit, ${ }^{4}$ Eran Kozer ${ }^{1,2}$
}

${ }^{1}$ Pediatric Emergency Unit, Assaf Harofeh Medical Center, Zerifin, Israel

${ }^{2}$ Sackler Faculty of Medicine, Tel Aviv University, Tel Aviv, Israel

${ }^{3}$ Department of Pharmacy, Assaf Harofeh Medical Center, Zerifin, Israel

${ }^{4}$ Department of Pediatric Emergency, Rambam Health Care Campus, Haifa, Israel

\section{Correspondence to} Dr Shiri Barkan,

Pediatric Emergency Unit, Assaf Harofeh Medical Center, Zerifin 70300, Israel; shiriraash@gmail.com

Received 13 December 2012 Revised 21 April 2013 Accepted 23 April 2013 Published Online First 18 May 2013
CrossMark

To cite: Barkan $S$, Breitbart R, Brenner-Zada G, et al. Emerg Med J 2014;31:649-653.

\begin{abstract}
Objectives To compare the efficacy of oral midazolam alone with a combination of oral midazolam and ketamine in children requiring laceration repair. Design A randomised, double-blind, placebo-controlled study.

Setting Paediatric emergency department.

Participants Children 1-10 years of age with lacerations requiring sedation.

Interventions Using a computer-generated sequence, children were randomly assigned in blocks of four to one of two groups: oral midazolam $(0.5 \mathrm{mg} / \mathrm{kg})$ plus oral placebo and oral midazolam $(0.5 \mathrm{mg} / \mathrm{kg})$ plus oral ketamine $(5 \mathrm{mg} / \mathrm{kg})$. The allocation sequence was kept by the pharmacy staff, and the investigators were blinded to randomisation until statistical analysis of the study was completed.
\end{abstract}

Main outcome measures Visual Analogue Scale (VAS) assessment by a parent and Sedation Score assessment by an investigator.

Results 60 children were recruited; 29 were assigned for treatment with midazolam and 31 for the combination of midazolam and ketamine. There were no differences in basic demographics and wound characteristics between the groups. VAS assessment by a parent was $4.5 \pm 3.3 \mathrm{~mm}$ in the midazolam+ketamine group versus $4.4 \pm 2.7 \mathrm{~mm}$ in the midazolam alone group (mean difference $0.1, \mathrm{Cl}-1.9$ to 1.71). Sedation Score during procedure was lower in the midazolam+ketamine group (mean difference 1.14, 95\% $\mathrm{Cl} 0.67$ to 1.6). Intravenous sedation was required in two $(6 \%)$ of the children in the midazolam+ketamine group, and in eight $(27 \%)$ in the midazolam alone group. $p=0.039$. No clinically significant adverse effects were documented in either group.

Conclusions No difference was found in pain assessment during local anaesthetic injection between the group treated with midazolam and ketamine, and the group treated with midazolam alone. The combination of oral midazolam and ketamine led to deeper sedation than midazolam alone, with less children requiring intravenous sedation.

Clinical trial registration The trial was registered in www.clinicaltrials.gov as NCT01470157.

\section{INTRODUCTION}

Oral midazolam is a commonly used sedative for children undergoing procedures such as laceration repair. Midazolam, a benzodiazepine that provides amnesia, muscle relaxation and anxiolysis, was shown to be better than placebo for procedural sedation. ${ }^{12}$ However, the reported efficacy of oral midazolam is only $60-76 \%,{ }^{13}$ meaning, that up to $40 \%$ of children who were treated with midazolam alone, stayed awake and active, and required intravenous sedation or the use of restraining techniques. Adverse effects of oral midazolam, such as agitation and respiratory depression resulting in oxygen desaturation, are rare. ${ }^{2} 4-7$ These reactions have been shown to be dose dependent. In a few studies, oral ketamine sedation has also been used successfully: for wound care procedures in children with burns, ${ }^{8}$ for invasive procedures in paediatric oncology patients, ${ }^{9}$ and for children requiring laceration repair. ${ }^{10}$ Younge et al ${ }^{11}$ compared high oral doses of ketamine $(10 \mathrm{mg} / \mathrm{kg})$ with midazolam $(0.7 \mathrm{mg} / \mathrm{kg})$ for sedation of children requiring laceration repair. This study showed better tolerance to local anaesthetic injection with oral ketamine, describing only minor, non-significant adverse effects. Green et $a l^{12}$ investigated the optimal dose of intramuscular ketamine, and concluded that ketamine doses of $4-5 \mathrm{mg} / \mathrm{kg}$ intramuscular produced adequate sedation in $93-100 \%$ of children. The optimal oral dosing for ketamine that provides appropriate sedation with minimal or no adverse effects has not been determined yet. Common known adverse effects of ketamine include vomiting, transient ataxia and drowsiness. ${ }^{10-13}$ Oxygen desaturation is a rare complication described only with intravenous or intramuscular delivery. ${ }^{12}$ The efficacy of the combination of oral midazolam and oral ketamine for procedural sedation has been studied for invasive procedures in children with malignancies, ${ }^{14}$ during intravenous cannulation in children undergoing CT imaging, ${ }^{15}$ and as premedication for short invasive procedures. ${ }^{16-20}$ It was concluded that this combination is as effective as similar combinations using rectal or intravenous route. To the best of our knowledge, there is no published, randomised, controlled study which compares oral midazolam alone to the combination of midazolam and ketamine, for sedation during laceration repair. We hypothesise that a combination of oral midazolam and oral ketamine can provide better sedation than midazolam alone without causing significant adverse effects.

\section{METHODS}

We conducted a prospective, randomised, doubleblind, placebo-controlled study. The study included children aged 1-10 years, who required sedation for laceration repair at the paediatric emergency department (ED) of Assaf Harofeh Medical Centre, A university-affiliated hospital in central Israel. The 
study was approved by the institute's ethics committee, and was registered in clinicaltrials.gov as NCT01470157.

\section{Patients}

Children aged 1-10 years requiring sedation for laceration repair, who were admitted to Assaf Harofeh Medical Centre paediatric ED, were included in the study. Children with neurologic impairment, and children with hypersensitivity to midazolam or ketamine were excluded from the study. Children were also excluded if they had other known contraindications for the study drugs, for example, hypertension, hyperthyroidism, glaucoma or known psychiatric disease; American Society of Anesthesiology (ASA) score of more than 2, or if informed consent could not be obtained from a legal guardian.

\section{Intervention}

Randomisation

Using a computer-generated sequence, children were randomly assigned in blocks of four to one of two groups (ketamine or placebo). The allocation sequence was kept secret by the pharmacy staff, and the investigators were blinded to randomisation until statistical analysis of the study was completed.

\section{Medication preparation}

Medications were prepared by the medical centre's pharmacy according to the randomisation sequence, and delivered to the ED tagged only with the study serial number. Ketamine vials contained ketamine hydrochloride $50 \mathrm{mg} / \mathrm{ml}$ (Pfizer (Pfizer, Pfizer Pharmaceuticals Group, New York, New York) or Ketamine-Ratiopharm Germany). Ketamine-hameln, Germany, The placebo vials contained normal saline. Both products contained clear liquid solutions, and looked alike.

\section{Sedation administration}

On arrival to the ED, lidocaine, epinephrine and tetracaine (LET) was applied to the laceration area by the triage nurse. Informed consent was obtained from legal guardians. A presedation questionnaire was completed by an investigator. As stated above, only children with ASA scores of I and II were assigned to the study. Oral premedication was given by the ED nursing staff: oral midazolam was given first, in a dose of $0.5 \mathrm{mg} / \mathrm{kg}$ (max. dose $15 \mathrm{mg}$ ). Oral ketamine or placebo was given next, in a dose of $5 \mathrm{mg} / \mathrm{kg}$. All solutions were flavoured with sweettasting syrup.

\section{Patient monitoring}

Following drug administration, heart rate, blood pressure, respiratory rate and arterial haemoglobin saturation were recorded continuously and documented every $5 \mathrm{~min}$. The level of sedation was documented by using a sedation scale. ${ }^{11}$ The scale has five levels of sedation ranging from 5 (agitated) to 1 (barely arousable, asleep, needs shaking/shouting to arouse). The procedure began only when a sedation level of four or lower (awake, calm) was achieved. Had the patient failed to achieve a sedation score of at least four within $30 \mathrm{~min}$ from drug administration, failure of sedation was documented, and intravenous sedation was administered. Prior to suturing, intradermal lidocaine (1\%) was administered to all patients. Laceration repair was conducted by the treating ED physician.

\section{Data collection}

Laceration location, drug dosing and time from drug administration to a sedation scale $\leq 4$ were documented. One of the parents (according to the parent's preference if both were present) was instructed on using the Visual Analogue Scale (VAS). VAS was assessed by an investigator prior to procedure, and measured during local anaesthetic injection by an investigator and by a parent.

All adverse events were documented. Adverse effects were defined as all clinically relevant events and sedation events resulting in an intervention or a change in disposition from the ED. ${ }^{21}$ Additionally, procedure time (from the moment of bandage removal and disinfection of laceration area, to bandage application at the end of suturing) and time to discharge from the ED were documented.

\section{Discharge from the ED}

Post-procedure, all children were continuously monitored in the ED until discharge. Children were discharged from the ED after they regained full consciousness, were able to sit or stand by themselves, drank without difficulties, and were haemodynamically stable.

\section{Outcome measures}

The main outcome measures included VAS assessment by a parent and Sedation Activity Score assessment by an investigator. Secondary outcome measures included the number of children who required intravenous sedation, VAS assessment by an investigator, time to sedation scale $\leq 4$, procedure duration, time to discharge from the $\mathrm{ED}$, and frequency of adverse effects.

\section{Data analysis}

Descriptive statistics were used to describe the study population. Data was analysed using $t$ test or Mann-Whitney $U$ test for continuous data, and Fisher's exact test for categorical data. The level of significance for all tests was 0.05 . Statistical analysis was conducted using the SPSS (19th edition; SPSS) computer programme.

\section{Sample size}

Previous studies that used parental VAS assessment during laceration repair found a SD of $20 \mathrm{~mm}^{22}$ and $29 \mathrm{~mm}^{23}$ Assuming that $\mathrm{SD}$ is $25 \mathrm{~mm}, 26$ patients in each group were required in order to detect a $20 \mathrm{~mm}$ difference in the mean VAS score with a power of $80 \%$, and an Alfa of 0.05 . In order to overcome a possibly higher SD, we decided to recruit 30 patients for each group.

\section{RESULTS}

A total of 80 children were screened for the study. Two children did not meet inclusion criteria (one had an abnormal neurologic examination and one was obese). In 18 cases, the parents refused to participate in the study (figure 1). Sixty children were included in the study and were randomly assigned into one of two groups: 29 children in the 'placebo group' received midazolam and placebo, and 31 children in the 'research group' received midazolam and ketamine. There were no significant differences in the demographic data (age, sex and weight) between the two groups. (table 1) Most children suffered from facial lacerations $(86 \%$ in the placebo group vs $74 \%$ in the research group, $\mathrm{p}=0.33$ ), mostly of the forehead and chin. Other sites of lacerations included: fingers and toes, flank and forearms.

The study outcome measures are described in table 2 . Time course to achieving a sedation scale $\leq 4$ was similar in the two groups. The time from administration of sedation to the beginning of the procedure was also comparable between both groups. Sedation score was lower in the research group than in 


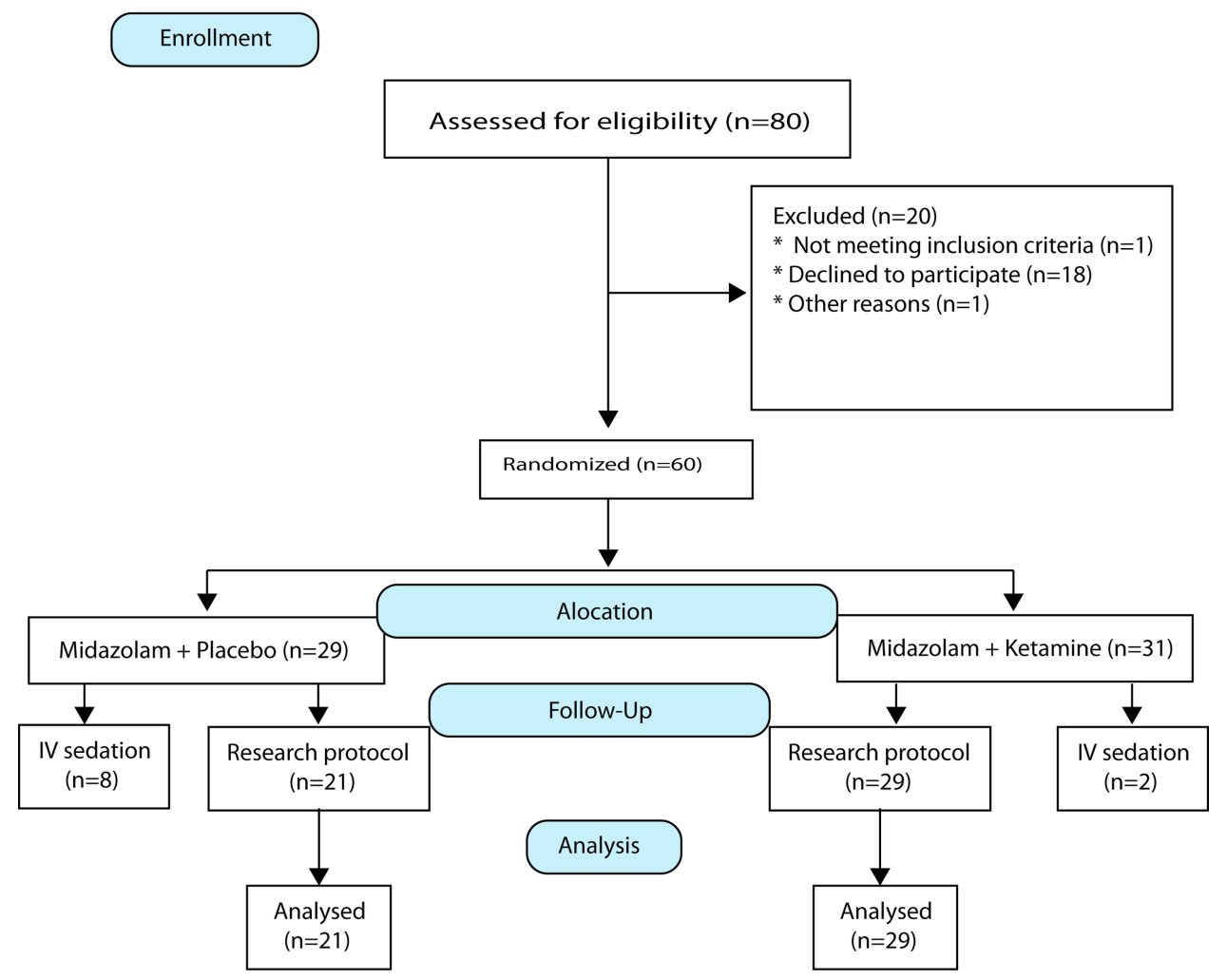

Figure 1 Patients' recruitment and allocation.

the placebo group, with a mean of $2.36 \pm 0.89$ and $3.5 \pm 0.67$, respectively (mean difference 1.14 , 95\% CI 0.67 to 1.6 ). Two $(6 \%)$ children in the research group and eight $(27 \%)$ in the placebo group required intravenous sedation $(\mathrm{p}=0.039)$. Procedure time was significantly longer in the research group $(15.75 \pm 6.53 \mathrm{~min})$ than in the placebo group $(10.9 \pm 5.32 \mathrm{~min})$, (mean difference $4.85 \mathrm{~min} 95 \%$ CI 1.28 to 8.42 ).

VAS score at the time of local anaesthetic injection, was comparable between the two groups, both by a parent $(4.40$ $\pm 2.78 \mathrm{~cm}$ and $4.50 \pm 3.33 \mathrm{~cm}$, respectively, and by an investigator $(4.49 \pm 3.16 \mathrm{~cm}$ and $4.05 \pm 2.87 \mathrm{~cm}$, respectively). Time to discharge from the ED was longer in the research group than in the placebo group (mean difference 65 min 95\% CI 22 to 107).

No severe adverse effects were noted during the procedure and recovery in the ED. In the research group, three children (9\%) suffered from vomiting; one child had a desaturation episode (SO2 <90\%) that lasted for a few seconds and spontaneously resolved, and two children were agitated after recovery. In the placebo group, one child had mildly low blood pressure, and one child was agitated. All adverse effects were mild, resolved spontaneously and did not require any medical intervention.

\section{DISCUSSION}

This prospective, double-blind study did not demonstrate differences in pain reduction during local anaesthetic injection, between children treated with a combination of oral midazolam and ketamine, and children treated with oral midazolam alone. Nevertheless, the combination of midazolam and ketamine led to deeper sedation (as assessed by the sedation score) and higher success rates, with a smaller number of children requiring intravenous sedation. Time to discharge from the ED was longer in the combination of oral midazolam and ketamine group, compared with the midazolam group.

Sedation is often needed for young children undergoing minor procedures in the ED. Although much research has been conducted on different sedation methods in children, a 'golden' combination of sedation drugs has yet to be discovered.

Table 1 Patients' characteristic

\begin{tabular}{|c|c|c|c|c|}
\hline Demographic characteristics & Midazolam+placebo $(n=29)$ & Midazolam+ketamine $(n=31)$ & Mean difference $(95 \% \mathrm{Cl})$ & p Value \\
\hline Age (years) $\pm S D$ & $5.26 \pm 2.26$ & $4.76 \pm 2.29$ & $0.5(-0.85$ to 1.46$)$ & 0.46 \\
\hline Weight $(\mathrm{kg}) \pm \mathrm{SD}$ & $18.12 \pm 5.92$ & $17.27 \pm 4.65$ & $0.85(-1.9$ to 3.6$)$ & 0.53 \\
\hline Male $(n=32) \pm S D(\%)$ & $15(51)$ & $17(54)$ & & 1 \\
\hline Facial laceration (\%) & $25(86)$ & $23(74)$ & & 0.33 \\
\hline Midazolam dose $(\mathrm{mg}) \pm \mathrm{SD}$ & $8.77 \pm 2.6$ & $8.63 \pm 2.32$ & $0.14(-1.14$ to 1.14$)$ & 0.83 \\
\hline Ketamine/placebo dose $(\mathrm{mg}) \pm \mathrm{SD}$ & $93.28 \pm 33.36$ & $84.52 \pm 23.42$ & 8.76 ( -6.06 to 23.58$)$ & \\
\hline VAS before procedure $(C M) \pm S D$ & $0.33 \pm 0.91$ & $0.41 \pm 0.98$ & $0.08(-0.47$ to 0.63$)$ & 0.77 \\
\hline
\end{tabular}


Table 2 Primary and secondary outcomes

\begin{tabular}{|c|c|c|c|c|}
\hline Variable & Midazolam+placebo $(n=29)$ & Midazolam+ketamine $(n=31)$ & Mean difference $(95 \% \mathrm{Cl})$ & $\mathrm{p}$ Value \\
\hline Procedure duration $(\mathrm{min}) \pm S D$ & $10.9 \pm 5.32$ & $15.75 \pm 6.53$ & 4.85 (1.28 to 8.42$)$ & 0.009 \\
\hline Time to achieving a sedation scale $\leq 4(\mathrm{~min}) \pm \mathrm{SD}$ & $17.93 \pm 6.9$ & $14.59 \pm 6.3$ & $3.35(-0.83$ to 7.53$)$ & 0.11 \\
\hline Time from drug administration to procedure $(\mathrm{min}) \pm \mathrm{SD}$ & $28.43 \pm 10.82$ & $24.76 \pm 7.17$ & $3.67(-1.85$ to 9.19$)$ & 0.15 \\
\hline Failure of oral sedation & $8(27 \%)$ & $2(6 \%)$ & & 0.039 \\
\hline VAS by investigator $(\mathrm{CM}) \pm \mathrm{SD}$ & $4.49 \pm 3.16$ & $4.05 \pm 2.87$ & $0.44(-1.29$ to 2.16$)$ & 0.61 \\
\hline VAS by parent $(C M) \pm S D$ & $4.40 \pm 2.78$ & $4.50 \pm 3.33$ & $0.1(-1.9$ to 1.71$)$ & 0.91 \\
\hline Sedation scale during procedure $\pm \mathrm{SD}$ & $3.50 \pm 0.67$ & $2.36 \pm 0.89$ & $1.14(0.67$ to 1.6$)$ & 0.001 \\
\hline Time from drug administration to discharge $(\mathrm{min}) \pm \mathrm{SD}$ & $121.76 \pm 31.20$ & $186.79 \pm 93.10$ & $65(22$ to 107$)$ & 0.003 \\
\hline Adverse events (\%) & $2(6.9)$ & $6(19)$ & & 0.26 \\
\hline
\end{tabular}

Comparatively little research has been performed on the use of oral ketamine for sedation in children, ${ }^{11} 14-20$ and most of it dealt with non-painful procedures, such as parental separation or mask acceptance. ${ }^{17}{ }^{20}$ Due to the scant data on the matter, the exact dosing of oral ketamine and its effect in combination with other drugs is not known.

The combination of oral ketamine and midazolam was described initially in 1993, in a study published only as an abstract by Lin et al who studied premedication for short surgical procedures. ${ }^{5}$ Their success rate using the combination was similar to that of each drug alone $(\sim 80 \%)$, though time to onset of sedation was shorter. No clinically significant adverse effects were noticed. Since then, several studies investigated the combination of ketamine and midazolam as premedication for short surgical procedures, ${ }^{17-20}$ for intravenous cannulation, ${ }^{15}$ and for invasive procedures in children with malignancies. ${ }^{14}$

Younge et $a l^{11}$ compared the effect of high dose $(10 \mathrm{mg} / \mathrm{kg})$ oral ketamine with midazolam $(0.7 \mathrm{mg} / \mathrm{kg})$ during laceration repair in children. The study found better tolerance to local anaesthetics and deeper sedation in children treated with ketamine with no difference in the overall rate of adverse events. Pain was not assessed in this study.

To the best of our knowledge, the use of the oral combination, midazolam and ketamine, for sedation of children during laceration repair, has not been investigated yet.

Our study found no difference between either group in the time to onset of sedation. Inconsistent findings were evident in previous studies. Funk et $a l^{18}$ investigated the oral combination of ketamine and midazolam as premedication for short surgeries. They compared three study groups: midazolam group $(0.5 \mathrm{mg} / \mathrm{kg})$, ketamine group $(6 \mathrm{mg} / \mathrm{kg})$ and a combination group (midazolam $0.25 \mathrm{mg} / \mathrm{kg}$ and ketamine $3 \mathrm{mg} / \mathrm{kg}$ ). The time course of the effect was similar in the three groups. Similar findings were shown by Ghai et al ${ }^{17}$ who compared the combination of midazolam $(0.25 \mathrm{mg} / \mathrm{kg})$ and ketamine $(2.5 \mathrm{mg} / \mathrm{kg})$ with midazolam $0.5 \mathrm{mg} / \mathrm{kg}$ alone, as premedication for short surgeries. Contrary to these findings, Darlong et $a l^{20}$ found that the time to achieve the best parental separation score was much shorter in the combination groups as compared with midazolam alone. At $30 \mathrm{~min}$, the parental separation scores were comparable in all study groups.

Contrary to our hypothesis, no difference in VAS score assessment was detected between the two study groups during local anaesthetic injection This finding might be explained by the fact that we used an indirect tool to assess pain. Since the study was conducted in young children, many of them less than 4 years of age, we could not use pain scales that are based on the child's self reporting. Conversely, sedation activity score was lower (better), and might be considered in future as a better assessment tool for sedation success in very young children.

Additionally, we found that procedure time was longer in the research group. Procedure duration depends on many variables, such as laceration size, laceration location, the physician on call and so on. The exact reason for the longer procedure duration in patients treated with midazolam and ketamine in our study is not known. One possible explanation is that despite randomisation, the patients in the combination group had more complicated wounds. Unfortunately, although some characteristics of the wound were documented, the laceration size was not documented; therefore, this assumption cannot be tested. However, if true, it may also explain why, under better sedation, the VAS assessment was comparable between groups.

Failure of oral sedation, and the need for intravenous sedation, may cause distress for the child and his parents, and requires additional human and medical resources. In our study, there were more children who required intravenous sedation among those treated with midazolam alone. These findings suggests that adding oral ketamine to oral midazolam significantly reduced the need for intravenous sedation and, therefore, should be considered in certain cases, such as complex wounds or significant agitation prior to the procedure.

Unlike previous studies, ${ }^{17}{ }^{18}$ children treated with the combination of midazolam and ketamine remained in the ED much longer than children in the placebo group. This finding might be explained by drug dosing. Previous studies ${ }^{17-20}$ did not find any difference in recovery time when children were treated with the combination of midazolam $0.25-0.5 \mathrm{mg} / \mathrm{kg}$ and ketamine $2.5-3 \mathrm{mg} / \mathrm{kg}$, whereas in our study, children were treated with higher doses of both midazolam $(0.5 \mathrm{mg} / \mathrm{kg})$ and ketamine $(5 \mathrm{mg} / \mathrm{kg}$.) The ketamine dose used in this study was based on the common dose for intramuscular ketamine. ${ }^{24}$ This relatively high dose was chosen because our study investigated sedation for a painful procedure, unlike previous studies. ${ }^{17-20}$ We should state that Younge et $a l^{11}$ used $10 \mathrm{mg} / \mathrm{kg}$ of oral ketamine for the same purpose with no clinically significant adverse effects. It is, however, important to remember that a longer stay in the ED means a higher cost for the health system. Therefore, one should consider the benefit of improving the depth of sedation versus the costs of observation for a longer time.

Our study demonstrated several limitations. First, although the combination of oral midazolam and oral ketamine was well tolerated, and adverse effects were mild and quickly resolved, due to the small number of patients, we cannot draw a definite conclusion regarding the safety of this combination. 
Second, we did not review the child's and parents' overall satisfaction from the procedure. We only assessed the VAS score at the time of local anaesthetic injection, which is a very stressful event, both for the child and for the parents. In many situations, agitation of the child was noted only during the injection, with full cooperation of the child and parental contentment afterwards. Lastly, another limitation was that recovery time was not documented properly ${ }^{21}$ and, instead, time to discharge from the ED was chosen as the secondary outcome.

Time to discharge from the ED in our study was $121 \mathrm{~min}$ in the placebo group and $186 \mathrm{~min}$ in the research group, while in other studies the average recovery time ranged from 70 to $128 \mathrm{~min}$ in the midazolam groups, and from 70 to $120 \mathrm{~min}$ in the combination/ketamine groups. These studies are not comparable as they deal with different procedures and different dosing. It is important to note that our study documented the time from administration of sedation to discharge from the ED as a secondary outcome, and not the time to recovery, as we believed it is a more objective measure. Yet in many cases, full recovery was achieved long before the child was discharged from the ED, for both technical and religious reasons such as: waiting for Shabbat to end, waiting for a ride, and so on.

In summary, our randomised, double-blind study demonstrated that treatment with a combination of midazolam $0.5 \mathrm{mg} / \mathrm{kg}$ and ketamine $5 \mathrm{mg} / \mathrm{kg}$ did not lead to better pain reduction during laceration repair, compared with midazolam alone. However, the combination leads to a better sedation, reduces the need for intravenous sedation, and has no additional clinically significant adverse effects except for a longer stay in the ED. Further studies should be conducted in order to determine the optimal dose, and to establish safety of the combination therapy.

Contributors All authors had full control of all aspects of the study design, data collection and analysis, and article preparation, and participated in the design of the study and the development of study definitions and instruments. EK and AA wrote the first draft of the study protocol which was critically reviewed by all authors. ShB, $R B, G B Z$ and MF were responsible for patients' recruitment and treatment. EK was responsible for the integrity of the data and the analysis. SB and MT prepared the drugs and patients' allocation. EK, IS and ShB were responsible for data analysis. EK and ShB drafted the initial article. All authors critically reviewed and approved the final version of the manuscript. EK takes responsibility for the paper as a whole.

\section{Competing interests None.}

Ethics approval The study was approved by the Institute Ethics Committee: Assaf Harofeh Ethics Committee Assaf Harofeh Medical Center Zerifin 70300, Israel. Contact: Ms Ortal Englander E-mail: ortala@asaf.health.gov.il Tel: 972-8-9779561. Fax: 972-8-9779118.

Provenance and peer review Not commissioned; internally peer reviewed.

\section{REFERENCES}

1 Davies FC, Waters M. Oral midazolam for conscious sedation of children during minor procedures. J Accid Emerg Med 1998;15:244-8.

2 Taiwo B, Flowers M, Zoltie N. Reducing children's fear when undergoing painful procedures. Arch Emerg Med 1992;9:306-9.
3 Silver T, Wilson C, Webb M. Evaluation of two dosages of oral midazolam as a conscious sedation for physically and neurologically compromised pediatric dental patients. Pediatr Dent 1994;16:350-9.

4 Hennes HM, Wagner V, Bonadio W, et al. The effect of oral midazolam on anxiety of preschool children during laceration repair. Ann Emerg Med 1990;19:1006-9.

5 Lin YC, Moynihan RJ, Hackel A. A comparison of oral midazolam, oral ketamine and oral midazolam combined with ketamine as preanesthetic medication for pediatric outpatients. Anesthesiology 1993;79:A1177.

6 McMillian CO, Sparth-Schopfer IA, Sikich N, et al. Premedication of children with oral midazolam. Can J Anaesth 1992;39:545-50.

7 Weldon CB, Watcha MF, White PF. Oral midazolam in children: effect of time and adjunctive therapy. Anesth Analg 1992;75:51-5.

8 Humphries Y, Melson M, Gore D. Superiority of oral ketamine as an analgetic and sedative for wound care procedures in the pediatric patients with burns. J Burn Care Rehabil 1997;18:34-6.

9 Tobias JD, Phipps S, Smith B, et al. Oral ketamine premedication to alleviate the distress of invasive procedures in pediatric oncology patients. Pediatrics 1992;90:537-41.

10 Qureshi FA, Mellis PT, McFadden MA. Efficacy of oral ketamine for providing sedation and analgesia to children requiring laceration repair. Pediatr Emerg Care 1995;11:93-7.

11 Younge PA, Kendall JM. Sedation for children requiring wound repair: a randomized controlled double blind comparison of oral midazolam and oral ketamine. Emer Med J 2001;18:30-3.

12 Green SM, Rothrock SG, Lynch EL, et al. Intramuscular ketamine for pediatric sedation in the emergency department: safety profile in 1,022 cases. Ann Emerg Med 1998;31:688-97.

13 McGlone RG, Ranasinghe S, Durham S. An alternative to 'brutacaine': a comparison of low dose intramuscular ketamine with intranasal midazolam before suturing. J Accid Emerg Med 1998;15:231-6.

14 Ozdemir D, Kayserili E, Arslanoglu S, et al. Ketamine and midazolam for invasive procedures in children with malignancy: a comparison of routes of intravenous, oral and rectal administration. J Trop Pediatr 2004;50:224-8.

15 Jain K, Ghai B, Saxena AK, et al. Efficacy of two oral premedicants: midazolam or a low dose combination of midazolam-ketamine for reducing stress during intravenous cannulation in children undergoing $\mathrm{CT}$ imaging. Pediatric anesthesia 2010;20:330-7

16 Dilli D, Dallar YH, Sorgui N. Comparison of ketamine plus midazolam versus ketamine for sedation in children during lumbar puncture. Clin J Pain 2009;25:349-50.

17 Babita G, Radhika Prasad G. Comparative evaluation of midazolam and ketamine with midazolam alone as oral premedication. Pediatric Anesthesia 2005;15:554-9.

18 Funk W, Jakob W, Riedl T, et al. Oral Preanasthetic medication for children: double-blind randomized study of combination of midazolam and ketamine vs midazolam or ketamine alone. British Journal of Anaesthesia 2000;84:335-40.

19 Banerjee B, Bose A, Pahari S, et al. A comparative study of paediatric oral premedication: midazolam, ketamine and low dose combination of midazolam and ketamine. J Indian Med Assoc 2011;109:386-8.

20 Darlong $V$, Shende $D$, Singh $M$, et al. Low- versus high-dose combination of midazolam-ketamine for oral premedication in children for ophthalmologic surgeries. Singapore Med J 2011;52:512.

21 Bhatt M, Kennedy RM, Osmond MH, et al. Consensus Panel on Sedation Research of Pediatric Emergency Research Canada (PERC) and the Pediatric Emergency Care Applied Research Network (PECARN). Consensus-based recommendations for standardizing terminology and reporting adverse events for emergency department procedural sedation and analgesia in children. Ann Emerg Med 2009:53:426-35.

22 Smith GA, Strausbaugh SD, Harbeck Weber C, et al. New Non-Cocaine-Containing Topical Anesthetics Compared With Tetracaine-Adrenaline-Cocaine During Repair of Lacerations. Pediatrics 1997;100:825.

23 Fatovich DM, Jacobs IG. A Randomized controlled trial of buffered lidocaine for local anesthetic infiltration in children and adults with simple lacerations. The Journal of Emergency Medicine 1999;17:223-8.

24 Green SM, Hummel CB, Wittlake WA, et al. What is the optimal dose of intramuscular ketamine for pediatric sedation? Acad Emerg Med 1999;6:21-6. 